\title{
Asymmetric representations of languages in contact: uses and translations of French and Spanish in Frasier
}

\author{
Roberto A. Valdeón \\ Universidad de Oviedo
}

In recent years, several authors have underlined the need for a critical approach to Translation Studies in order to explore power struggles in both source and target languages and cultures. Norman Fairclough's model of discourse analysis offers textual and interpretative procedures for the analysis of linguistic features of texts and their societal implications that can be successfully applied for this purpose. In this article we shall study the representations of languages and cultures in contact in the American situation comedy Frasier, one of the world's greatest television successes of the 1990s. We shall cover two distinct uses of languages in contact. In our first section, we shall examine the use of other languages in the primary English discourse of the protagonists, notably French and Spanish, and their different representational and ideational implications, before proceeding to analyse the Spanish and French target versions to ascertain whether the ideological components are maintained or transformed. In the second section, we shall analyse the scenes where two or more languages are involved and the transformative acts performed by the characters. As in the first section, the target versions in French and Spanish will then be examined in order to identify the translational strategies used to maintain or tone down the ideological components. The final section will discuss the last dimension of Fairclough's model, that is, sociocultural practice or explanation.

\section{Languages in contact and screen translation}

Speakers of two or more languages sharing the same linguistic event is certainly the situation most commonly associated with the notion of language contact and, in fact, this is the way in which it is generally referred to (Thomason 2001: 1-14). Language contact is so widespread that it could be taken to be the "norm, not the exception. We would have a right to be astonished if we found any language whose speakers had successfully avoided contacts with all other languages" (Thomason 2001: 10). The effects of this can be felt in a given communicative event in two major ways: as stated above, it can be realised in the use of two or more languages at the same time, or else, speakers can use stretches of a foreign language within their own mother tongue. Traditionally, both have been the source of comical situations in film and television comedies, as well as the origin of a very specific problem for the screen translator. Heiss (2004: 208-209) has recently acknowledged the difficulties of multiculturalism and multilingualism in modern Europe, but the problem has always existed to some extent or other. 
Zabalbeascoa (1996: 249) mentions, for instance, the case of the dubbing of a British sitcom from the 1970s, Fawlty Towers, where the inarticulate Barcelona-born waiter working in the environment of an inhospitable English hotel underwent a process of transformation in the Catalan version, which effected a change of nationality and made a Mexican of him to avoid cultural clashes between the source and the target cultures.

Moreover, as Fawlty Towers also shows, languages are associated with a specific culture. Their history and the history of their speakers also have an influence on the ways in which languages are perceived and, consequently, used, by non-native speakers. Thus, in recent years, issues such as the use of languages to dominate cultures and nations, on the one hand, and the appropriation of languages, on the other, have given rise to heated debates amongst researchers (Phillipson 1992; Widdowson 1994). The use of English as a dominant language has been challenged and the need to redefine the role of languages put forward (Phillipson 2003: 152-157). The United States of America is not alien to this debate, with issues such as the 'English-Only Campaign' in an increasingly multicultural and multilinguistic society. This country, the world's major producer of audiovisual fiction, has found it more and more difficult to resist the presence of speakers of other languages in its society, a situation that is reflected in Hollywood films and in television programmes. Language contact is all pervasive, as shown in recent films like Spanglish (2004) or sitcoms like Will \& Grace.

In this paper we intend to discuss the ways in which languages in contact are used in the original script of the popular American comedy Frasier, considering their representational and expressive values (Fairclough 1992: 167; 2001: 93ff) in the ST as well as in two dubbed versions. The writers of the comedy often resort to other languages to create comical effects, notably French, Spanish, Italian and German. As for the two major ways in which languages can interact mentioned above, the second is by far the more common in Frasier, with French being often assimilated by the protagonists as part of their own speech. Although two or even three languages may occasionally be used in this sitcom, for the discussion we shall concentrate on the uses of French and Spanish. Passing references will also be made to the other two.

In the first section we shall cover the way in which French and Spanish are embedded within the English discourse of the protagonists. We shall also examine the transformations the ST undergoes in the Spanish and French dubbed versions in order to establish whether the representational and expressive values have been altered in any way. In the second section we shall look at those scenes where English is not the only primary language, considering the contexts in which such scenes occur, and the ways in which the use of Spanish or French reveals perceptions that the original viewers may have of the culture of the Other or Others. Finally, we shall discuss the relationships between these three languages and their respective cultural backgrounds, as reflected in Frasier. 
To carry out the study we shall resort to a textual analysis of the tapescripts of the first two series, a total of 48 episodes recorded between 1993 and 1995. The reference to the episodes will indicate the season followed by the episode (i.e., 2.4. indicates the fourth episode of the second season). We shall use Mason \& Hatim's parameters for discourse analysis and its translation, complemented with Fairclough's proposals for textual analysis (1989, 1992, 1995). In recent years a number of translation scholars have suggested the need to implement a critical approach to TS by using tools from Critical Linguistics. Venuti (1998: 67) has underlined the role of translation in projecting certain representations of foreign cultures in literature. In the global panorama of the $21^{\text {st }}$ century this view can be even more aptly applied to the case of audiovisual materials, which have a massive capacity for reaching and influencing world audiences. Olk (2002) demonstrates the didactic potential of a critical approach in the teaching of translation, whereas Brownlie (2003) discusses it against the background of a range of related descriptive and committed approaches in Translation Studies.

In the final discussion we shall adapt some of the interpretative procedures suggested by Fairclough to the specific nature of the translation and its cultural implications. Fairclough's proposals for the interpretation of linguistic events complement Hatim \& Mason's approach to textual analysis since both draw on the functional framework proposed by Halliday \& Hasan (1976). Particularly relevant here will be Hatim \& Mason's references (1990: 89; 1997: 172) to the power implications of the lexical choices made by translators, as well as to the ideological implications derived from those choices (1997: 143). Drawing on Fairclough, they underline that "lexical selection tends to be a reflection of social role and status, and alternative lexicalisations may emerge from different ideological positions" (Hatim \& Mason 1990: 89). Thus, we shall deal with what Fairclough (2001: 135) terms explanation. This level involves a range of aspects that constitute social and cultural practice, including economic, political and cultural ones.

\section{French and Spanish in the primary discourse of Frasier}

\subsection{French and Spanish in the ST}

The script writers of Frasier often resort to other languages for the creation of humorous situations. French is the most common of the European languages being used. French proper names are particularly noticeable in the discourse of two Crane brothers, as the examples below show:

Ex. 1a

Frasier: I am not a piece of Lalique. I can handle criticism. How was I today? (1.1)

Ex. 2a

Frasier: You know, every item here was carefully selected. This lamp by 
Corbusier, the chair by Eames, and this couch is an exact replica of the one Coco Chanel had in her Paris atelier. (1.1)

Ex. 3a

Niles: How about an evening of fine dining?

Frasier: Perfect ... but where?

Frasier \& Niles: [excited] Le Cigare Volant!

Frasier: [ecstatic, wrings his hands] Hah! (1.3)

Ex. $4 \mathrm{a}$

Frank: [examining one of Frasier's objets d'art] This dish a Lalique or a Steuben? (1.15)

The use of French terms and phrases with a strong cultural component is obvious in the continuous references made by the Cranes to French products, wine in particular. This is a selection of some examples:

Ex. 5a

Niles: When he thought he was tasting the Château Pétrus, he was in fact sipping a Forcas Dupres. You see, we'd switched the labels. (1.5)

Ex. $6 \mathrm{a}$

Catherine: Mmm. That was the most delicious salmon Marseille I've ever tasted.

Frasier: Well, maybe you should try my "salmon-chanted evening".

Catherine: Oh, no. Tell me you didn't say that.

Frasier: No, it was just the Laffite talking. "Laffite don't fail me now".

Catherine: C'mon, stop, stop. (1.7)

Ex. 7a

Frasier: Well, enough talk about death. [produces a bottle of wine] Let's celebrate life with a bottle of Château Certair' 75. (1.11)

However, the most noticeable feature of the use of French by the protagonists is the incorporation of French words and expressions as part of their ordinary discourse, often in a superficial manner, including peripheral elements (Biber et al. 1999: 1082-1099) such as French response forms, polite formulae and salutations, such as Salut (1.22), Merci beaucoup (2.3), Silence (2.7). Other elements may also be used by Frasier and Niles Crane, ranging from exclamations of surprise, prepositions, and, of course, nouns:

Ex. 8a

Frasier: You've been retained.

Daphne: Oh, wonderful! I had a premonition.

Frasier: Quelle surprise.

Daphne: I'll move my things in tomorrow. (1.1)

Ex. 9a

Frasier: Let us get something clear. I am not a morning person. I have to ease into my day slowly. First I have my coffee - sans eggshells or anything else one tends to pick out of the garbage. (1.2) 
Ex. 11a

Martha: Dr. Crane? I'm Martha Paxton.

Frasier: Of course, who else could you be? Welcome to my salon. [loudly] Everyone, everyone, your attention, please. I'd like you all to welcome our guest of honour, the renowned artist - Martha Paxton (...) I recently gave a small but elegant soiree at which Martha Paxton was in attendance, you see. (1.6)

Ex. 12a

Frasier: This is fantastic! Let's celebrate with a nice dinner at an exclusive boîte?

Niles: Yes, but the question remains, what boîte?

Frasier: Charise?

Niles: Too noisy.

Frasier: Alsace?

Niles: Too bright.

Frasier: Papillion?

Niles: Too crowded.

Frasier: We've run out of boîtes.

Niles: A city this size and only three boîtes. (2.5)

Spanish does not receive the same prominence as French in the speech of the brothers. In fact, they rarely use it, which may be partly due to the fact that Spanish has not traditionally conveyed the notion of refinement so dear to the Cranes. This language tends to be used by other characters, who are usually looked down upon by the protagonists. Thus, Spanish is rarely used linked to sophistication, but rather to much more down-to-earth elements such as money or courage. References to native speakers of Spanish (of nonEuropean descent in all cases) are far less flattering too. For example, the allusion to the speech of Niles Crane's maid is presented as "She began screaming what I gather were some very unflattering things in idiomatic Guatemalan" (1.17). As for the incorporation of Spanish in the discourse of the characters, it can be traced in the speech of macho-type Bulldog, the sports commentator at Frasier's radio station, and Martin Crane, Frasier's father and a retired police officer. Some examples follow:

Ex. 13a

Bulldog: No problem. Doc, doc, with all due respect, you're an idiot. These promos are easy money.

Frasier: The money is irrelevant. It's a question of integrity.

Bulldog: Integrity? [raps on Frasier's forehead] Hello? We're talking mucho dinero. But hey, the more you turn these down, the more liver snacks for the Bulldog. (1.9)

Ex. $14 \mathrm{a}$

Martin: Well, that's all right, it's still better this way! At least he's found his manhood.

[Daphne comes out of the hallway.]

Martin: I tell ya, I'd be happy if Niles traded in a couple of teeth for his cojones! 
[Frasier leaves.]

Daphne: I've got to stop walking in on the middle of conversations! (2.21)

Spanish may also be used for cultural references, although they do not project the image of class and distinction that it is intended whenever French is used. Thus, in the introduction of Martha Paxton, and after kindly asking the artist to meet his friends in his salon, he addresses Martha thus:

\section{Ex. $15 \mathrm{a}$}

Frasier: May I take your ... poncho?

Martha: No, no, no, no, I never take it off at parties. It gives me an excuse not to shake hands with people.

Frasier is reluctant to mention the name of the garment that his very exclusive guest is wearing, but he does not seem to find a way out. Hence, the moment of doubt. To Frasier's bewilderment, Martha aligns herself with Martin and Bulldog here as the apparent reason for wearing this piece of clothing seems to indicate a desire not to mingle with Frasier's lot. On the other hand, the Cranes may make an occasional reference to Spanish goods, as when Niles says he bought his very expensive shoes "from a little blind cobbler in Seville" (1.20).

Finally, Italian and German are also used, although usually restricted to operatic references. Italian is also often used in the Café Nervosa, where Niles will order in Italian to the astonishment of the waiters. He will come in and order Caffè latte per piacere, and use the Italian polite formula Mille grazie when he is finally served. German cultural references or expressions may occasionally be used outside operatic contexts but in those cases the Crane brothers seem to be rather out of touch. It is Martin who might mention German beers or food, which the brothers dismiss since these goods do not provide the same touch of class as a French wine or dish.

\subsection{French and Spanish linguistic and cultural references in the TTs}

The cultural references made in the ST might have a different appeal to different audiences. The perspective of a European Spanish audience might somewhat differ from that of American viewers. However, within the globalized media market of the late $20^{\text {th }}$ century many of the references could certainly be identifiable, particularly within western societies which are likely to share similar values, opinions or feelings about given stereotypes. In Zabalbeascoa's words (1994: 95) some degree of "shared knowledge" is required since references need fast identification to be quickly assimilated by the audience or else the effect will be lost. But it is not just "shared knowledge" that is needed but also a "shared perspective" on that knowledge, i.e. a similar interpretation of the references that are shared by the source and the target audiences. In the case of cultural references to French goods, the TT 
in French keeps them all. Expensive wines and cheeses as well as other household names associated with luxury goods, such as Chanel and Le Corbusier, are maintained in the French version. Obviously, the French audience is certain to pick up the majority of these references to their culture, even if they cannot necessarily afford to buy the goods mentioned by the Crane brothers.

The Spanish TT also maintains many of those culture-specific references, notably the names of French products such as wines or luxury goods:

\section{Ex. $5 b$}

Cuando creía estar degustando un Château Pétrus, lo que en realidad bebía era un Fourcas-Dupré.

Ex. $7 b$

Celebremos la vida con una botella de Château Certan del 75 .

Occasionally, there may be important deviations from the original cultural reference, and the TT version might not reflect in any way the meaning or the intended implication. In fact, in the Spanish rendering of Ex. 6a the viewer would simply be unable to comprehend Frasier's apparent joke, signalled by the canned laughter, since the name of the expensive wine has been rendered as mayordomo:

Ex. 6b

Catherine: No te pega nada decir eso.

Frasier: Es el mayordomo el que habla. Mayordomo no me falles.

Certain other culture-specific names are omitted. For instance, the reference to Lalique disappears in the Spanish version, which translates the word as porcelana. The translator may have judged that the audience would not be familiar with the term, and, therefore, opted for the use of a superordinate word in order to overcome the difficulty posed by the ST. However, it is doubtful whether this strategy is successful in a case where the target lexical item does not necessarily convey the nuance of sophistication intended by the ST term.

As for the renderings of other French lexical items in the ST, the strategies are varied. It must be noted that, whereas in the previous examples proper names with a strong cultural component cut right across language boundaries (even though the effect on the audience might differ), in the case of the incorporation of other French words and expressions, the translator is confronted with much greater difficulties, particularly when rendering them into French. Let us consider the TTs of some of the examples quoted above to illustrate the three combinations of translation strategies we have identified.

Firstly, French expressions may remain unaltered in the TT. Thus, the exclamation used in Ex. 8a is maintained in both the French and Spanish 
TTs. In the original version, the comic effect of Quelle surprise! is signalled by the background laughter. This is maintained in both versions, but only the Spanish one seems to make any sense here. French viewers would be at a loss to interpret the reason for the laughter.

Secondly, a French element may be maintained in the same form in the French version, eliminating the intended effect on the audience, but altered in the Spanish version. That happens to Ex. 9a where the whole stretch is rendered into Spanish, with no compensation strategy for the loss that the use of sans was intended to have in the characterization of the protagonist.

The third option may sound rather curious: it involves maintaining the term in the Spanish TT but changing it in the French. For example, in Ex. 12a, translators kept the word boite in the discourse of Frasier in Spanish, whereas they opted for bistrot in the French version:

\author{
Ex. $12 b$ \\ Podríamos celebrarlo con una buena cena en una boîte exclusiva. \\ Sí, pero he aquí el dilema ¿en que boîte? \\ Ex. 12c \\ ... un bistrot à la mode. \\ Oui, mais le dilemme atroce est quel bistrot?
}

Once again, the choices will certainly have a different effect on the audience. French viewers are less likely to understand the ironical approach of the script writers to the Crane brothers. The first problem encountered by the translators is the cultural difference that the word boite may entail in the target language. Thus, they have opted for a different term, bistrot, which suggests the meaning of the original. As regards the Spanish version, the option to maintain the original word retains the tone of the ST, but it also introduces a contradiction since the item is (or rather was) used in Spain in the 1960s with very much the same meaning as in French. The quest for a small French restaurant is part of the characterization process of the protagonists. The French TT recovers some of the connotative meaning of the original term in the ensuing conversation thanks to the French names of the restaurants, but the Spanish choice to keep boite may be puzzling since, although the French names of the restaurants might compensate for the semantic deviation, the fact is that some of the comments made by Niles will add confusion rather than clarification (Spanish viewers might wonder: how can a boîte not be noisy or crowded?).

Finally, the French expressions in the ST may undergo alterations in both TT versions. Ex. 12a provides us with good examples of this. The term used by Frasier to welcome his very special guest is salon. The word here is in keeping in with the pedantic tone of his speech. Salon is used both in French and Spanish with a similar meaning but it does not carry the connotation implied in the ST of the sitcom. For this reason, the term is rendered as a plural in Spanish, salones, and as demeure in French. The foreignizing 
element is lost, but the ultimate goal of the script, i.e. portraying Frasier as ridiculously pedantic, is maintained.

Finally, as regards the use of French peripheral elements in the TTs, both the Spanish and French versions keep all the original elements. The effect, therefore, varies considerably, since, while the use of French inserts retains the foreign flavour for a Spanish audience, in the French version the audience will be unaware of the use of their language and the intended effect. For instance, in Episode 1.3 the effect of choices such of Merci and $\grave{A}$ bientôt stand out in the Spanish version but simply disappear in the French one.

As for the Spanish expressions and cultural references made in the ST, the treatment is somehow different. The items used are not always retained in the Spanish TT. Fewer references to cultural elements from Spanish-speaking countries are maintained although the effect varies. Thus, Frasier's rather negative use of the term poncho in Ex. 16a is not reflected in the Spanish and French versions, where the character does not seem to convey the same degree of contempt for the term. As regards the incorporation of Spanish expressions in the speech of Bulldog and Martin, the strategies also vary. The Spanish version maintains the expletive used by the latter in Ex. 15a, but the French version uses the anatomical term, testicules. Conversely, Ex. 14a remains as in the original in the French TT, whereas the Spanish TT has altered the discourse to make it sound more colloquial:
Ex. $13 b$
Le hablo de mucha pasta gansa
Ex. $13 \mathrm{c}$
Là je te parle de mucho dinero

The Spanish translators have interpreted the use of these expressions as a marker of informality to characterize Bulldog and Martin, who often resort to colloquial expressions and other features of informality in English such as ellipsis of subjects and auxiliaries. The use of Spanish in Ex. 13c would not have had that effect, since the expression is neutral in Spanish. The choice of a slang expression keeps, thus, the tone. As regards Ex. 14c, the Spanish might sound much stronger. Martin's use of the Spanish term cojones can be easily associated with the speech of a retired policeman. Although it is an expletive in Spanish, it also has the status of a euphemism in English, since the characters of this sitcom do not resort to foul language. In Spanish, the translator has kept the expletive ("Nada me alegraría más que cambiase un par de dientes por un par de cojones"), and even though the word is extremely common, the effect is much stronger precisely because none of the protagonists ever swears, not even in moments of tension. The French option sounds, no doubt, ridiculous since no compensation strategy has been used for the loss of an expletive aimed at portraying Martin as an angry old man. In fact, Martin is very unlikely to use testicules, which the French version presents. 


\section{French and Spanish as primary discourse in Frasier}

\subsection{French and Spanish in the ST}

Apart from the incorporation of French and Spanish cultural references and lexical items into the speech of the protagonists, the script writers also resort to the occasional use of these two languages as primary discourse, that is, they may be used instead of English. In this section, we shall concentrate on two examples. In the first one, the Crane brothers slip into French, whereas in the second example Spanish (and German) feature prominently. Let us consider the extracts first:
Ex. 16a
Frasier: You know, Niles, perhaps it's best we don't discuss the operation. We might spook him
Niles: Excuse me? Are you saying he understands me?
Frasier: Well, he understands the word B - A - T - H. God knows how much English he's picked up.
Niles: Fine. Tu tournes à droite.
Frasier: Ah, bon, bon. Je marcherai derrière lui.
Niles: Mais, tu es celui qui vas l'amener chez le médecin pour le ... snip-snip. Frasier: Ah. C'est vrai, mais ... oh, what are we doing? Eddie, come here! This is ridiculous. Look at him. Oh, for Pete's sake. (2.2)
Ex. $17 \mathrm{a}$
Niles: Marta! You speak German?
Marta: ¿Qué?
Frasier: Uh, ¿habla alemán?
Marta: Si! Yo trabajé para una familia alemana que llegó a Guatemala después a la Guerra.
Frasier: Apparently she worked for a German family that turned up in Guatemala ... [deep voice] just after the war.
Niles: Well, well, good, good! She can translate for me! Tell her to tell him (...) Hang that, Frasier! If there're going to be scuffs, they'll be scuffs of honor. [to Gunnar] How dare you steal my wife! [to Frasier] Translate!
Frasier: Oh, all right. [to Marta] Señor Crane quiere que preguntas a Gunnar, uh," ¿Cómo se atreve a robar mis zapatos?" (2.21)

The need to create a farcical effect clearly determines the use of foreign languages in these extracts. In the first one, the Crane brothers use French to avoid being understood by the dog until Frasier realises how silly the situation has become. In the second example, Marta, Niles' wife's Guatemalan maid, cannot speak English, and neither can her German fencing instructor. The former, however, happens to speak some German. Suddenly we learn that Frasier speaks Spanish and, thus, Marta ends up interpreting for Frasier, who, in his turn, interprets for Niles. A major misunderstanding occurs since wife is translated as zapatos by Frasier, and, later on, back-translated as shoes. 
The use of these two foreign languages supplanting English responds to a similar objective, that is, to create inauspicious situations for the characters and, consequently, produce the desired comical effect in the audience. This is achieved by allowing for some inconsistencies in the characterization of the protagonists. On the one hand, the Crane brothers are fond of German operas and often quote them in other episodes. This is certainly incongruous with episode 2.21 in which neither can communicate with the German character and alleged lover. On the other hand, it does not seem plausible that two eminent psychiatrists, Frasier a self-confessed Freudian and Niles a Jungian, should not be able to read their masters in their original language. Still, for the sake of comedy, the script writers have obviated these details, and the fact remains that the scenes require interpreting as part of the linguistic misunderstandings.

\subsection{French and Spanish in the TTs}

The translation of these scenes into the target languages varies considerably. Firstly, it must be realized that the transformative acts into French and Spanish respectively pose a great problem since either the former or the latter are present in the ST too. In the case of Ex. 16a, and as regards the Spanish TT, French is maintained as in the original; that is, the TT uses Spanish when the brothers use English and makes no changes to the French stretch. Conversely, the French version encounters a major difficulty since the Crane brothers are already using French. The preferred option here is English, although this is used sparingly. In fact, the ST is translated almost as a whole while a few English words are introduced to indicate what else might be going on here:

\section{Ex. 16c}

Niles: Fine. You turn on the droite.

Frasier: Ah, bon, bon. Je marcherai derrière lui.

Niles: Mais, tu es celui qui va l'amener chez le médecin pour le ... snip-snip. Frasier: Ah. C'est vrai, mais...

The original text aimed at showing the ridiculous situation which the pedantry of the Crane brothers had given rise to, while the French version is more inclined to maintain the message rather than reproduce the farce. As regards the translation of Ex. 17a, the French version remains fairly faithful to the spirit of the original, except for the fact that, occasionally, certain French lexical items are used instead of Spanish, in keeping in with the tendency to tone down the use of other languages and favour the semantic content of the discourse rather than the ultimate implication. Thus, Frasier says Habla allemand? rather than alemán. But for the most part, since Frasier and Marta are both translating, English is relayed as French, Spanish remains Spanish, and German remains German. 
In Ex. 17a, however, a problem arises for the Spanish translators, since the comical effects of the scene depend on the interpreting carried out by Frasier and Marta, speaking in Spanish in the ST. The choice made by the translators to surmount the difficulty is to turn Marta into a French speaker whereas Frasier interprets for his brother:

\author{
Ex. $17 \mathrm{~b}$ \\ Marta: Quoi? \\ Niles: ¿Habla alemán? \\ Frasier: Vous parlez allemand? \\ Marta: Oui, j'ai travaillé pour une famille allemande qui est arrivée à Paris \\ après la guerre.
}

This option is, in principle, appropriate. The context enables a native French speaker to justify that Marta speaks German, since France and Germany are neighbouring countries and were opposed during World War II. Frasier's knowledge of French, used elsewhere for characterization, as he translates for his brother, might also seem reasonable, and the Spanish audience can easily follow the political and historical elements implied. However, on closer observation, this choice makes the TT rather inconsistent intratextually, if we consider the fact that both brothers are constantly characterized as Francophiles, and that they may even use French themselves (as in Ex. 16a). Therefore Niles would never have needed his brother to act as an interpreter for him.

\title{
4. Interpretation and conclusions
}

In Fairclough's framework, the interpretation stage relies on three elements, schemata, frames and scripts (2001: 134-137). Schemata represent particular types of activity, frames refer to the subject matter, and scripts to the subjects involved in those activities. Text consumers, or, in this case, viewers, are endowed with particular interpretative procedures connected with their own experience, which would allow them to view Frasier in a particular way. In the case of the discourse or discourses we have examined, the interpretation of an English-speaking audience would certainly differ from that of a French audience, and, of course, from the interpretation of Spanish viewers.

Frasier uses languages, as already stated, to create humorous situations and, thus, to achieve its ultimate goal of meeting the expectations of the audience and being successful in the television market. The writers partly rely on interpretative procedures shared with the primary audience, that is, their English-speaking viewers. The use of French helps the characterization of the Crane brothers as obsessed with class, distinction, luxury. They eat at French restaurants, enjoy expensive French wine and food, and even use French occasionally. French and references to various French goods are used to project this image onto the audience. Overlapping of the three elements 
mentioned above may occur (Fairclough 2001: 132), and, in fact, in the case of Frasier, the Crane brothers can both be regarded as mental typifications as well as the perfect embodiments of pedantry. In any case, the French language functions as an element capable of conjuring up some of the experiential representations of stereotypes the audience may be familiar with.

Spanish, on the other hand, is not so unmistakably marked, but there are indications that the use of this language evokes very different images. Spanish does not represent the same degree of sophistication and social distinction. Whereas French relates to class, Spanish is used to express anger (as in cojones), or to refer to monetary issues (mucho dinero). Even when used extensively, as in Episode 2.21, the speaker is a Guatemalan maid working for Niles' wife and the audience might be surprised to learn that Frasier can speak Spanish. The explanation for this different positioning of Spanish visà-vis French relies on the different perception that both the writers and the audience have of the most likely speakers of Spanish they may encounter in the United States, that is, immigrants from Latin-America who usually carry out low-skilled jobs, as in the case of Marta. Even Bulldog and Martin Crane are more likely to have met some of them either socially or professionally, and, for this reason Spanish may have made an impact on their discursive features.

As regards the two target versions examined here, the embodiment of ideological representations of the characters as epitomes of snobbery, portrayed through their use of French, is partially lost even if most cultural references are maintained in both TTs. However, the frequent use of French as part of the set of linguistic conventions of the protagonists disappears in the French TT, and, consequently, many of the comic effects in Frasier are lost in the French version. Thus, "comic equivalence" (Zabalbeascoa 1994: 96) is only partially achieved, since compensation strategies are rarely used in these cases. For instance, the use of salon in Ex. 11a is relayed in the French version as demeure, which underlines Frasier's pretentiousness but avoids connecting it with his use of French words. The reason for this might well lie in the translational difficulty we pointed out. But then, this difficulty could also act as a pretext under which the (secondary) target audience may be spared an ideologically threatening use of their own language. After all, the use of French (and, less often, Italian) serves in the original to portray the Crane brothers as complacent, pedantic and vain. French brand names, on the other hand, represent class and distinction; not surprisingly, they are preserved, as are the Italian ones.

The Spanish version, on the other hand, maintains all the French loans, and the effects achieved are similar to the ones in the original version, since the implications involving the semantic content, the characters and the relations among them are similarly relayed into Spanish. Consequently, the effects on the audience are very much the same: French enjoys a status of superiority in the Crane household vis-à-vis Spanish (which tends to disappear in the TT) as well as other languages. The translators have relied on the similar representational values that the French language and French goods 
have traditionally had in Spain. Until the 1980s French was taught as a foreign language in most Spanish schools, French culture was admired and French goods were coveted. In this sense, the translators have had little trouble to relay the ST into Spanish. However, it is doubtful whether this representational value still prevails for a younger Spanish audience today, which might be more inclined to challenge traditional stereotypes, and, in particular, the use of Spanish and Spanish references. Thus, Niles' reference to "the little blind cobbler in Seville", who made the very expensive shoes he is wearing, risks being contested by an audience more likely to associate Spanish shoes with a global and highly developed industry than with a $19^{\text {th }}$ century Bizet-like shoemaker. Furthermore, the transformation of the Guatemalan maid into a French-speaking Marta may respond to the linguistic difficulties derived from the challenge posed by the three languages in contact in the episode. But it could also be a convenient way of avoiding ideological conflict with the Spanish audience. It might even have a subsidiary positive effect on the viewers in order to compensate the asymmetrical use that the original script writers make of Spanish and French in Frasier.

As pointed out by Hatim \& Mason (1990: 86), "the relative power and status of language users within social institutions exercise a determining influence not only on language forms used but also on the intended and perceived illocutionary force of utterances", but this status is by no means unalterable. Thus, we come to the last stage in this final section, which attempts to provide what Fairclough (2001: 135-139) terms an "explanation". Over the past three decades, the social, political and economic situation in the West has evolved in ways which affect our perception of the Other/the Others. In the case of Frasier, the writers make extensive use of the traditional schemata about French and Spanish languages and cultures, but this use does not necessarily imply accepting those typologies. In fact, the contact between English and French in Frasier projects on to the audience a very negative image of the Crane brothers as vain, arrogant and conceited. This image relies very much on the use, and even abuse, of French motifs, which involves problematic situations in which the participants (the Crane brothers on the one hand, other characters on the other) do not interpret those linguistic and cultural elements harmoniously (Fairclough 2001: 137). French occupies a central position in the representation of class, whereas Spanish would sound less appealing. Thus, the two languages are asymmetrically used within the series.

However, this representation is by no means consistent. French might convey certain values regarded by the audience as positive, but its constant and excessive use also projects a certain degree of intratextual asymmetry, that is, when compared with previous sitcoms in which French played a more positive and coherent role. If we watch just one episode of Frasier, the use of French would certainly stand out as part of the characterization process of the Crane brothers, perhaps in a positive way. But as viewers complete the picture with all the episodes (at least the 48 episodes of the first two series), we realize that the traditional representative values of French products, and 
of the language itself, are combined with other connotative meanings, less appealing as a whole. This might reflect what Fairclough (2001: 122) calls the nature of change in society, since the meanings and forms in which the language contact takes place within the sitcom are in no way homogeneous.

The asymmetric use of foreign languages also remains a feature of the Spanish version since French is also projected with the negative effects commented above. However, the most important loss in this representation of language contact affects the French version of Frasier because this language does not normally convey the same degree of conflict between the participants, and between languages and cultures in contact, as French terms and expressions tend to disappear in the TT. This might be due to the constraints imposed by the ST, but, as indicated, it might provide a good justification to avoid face-threatening events for the French target audience. In this sense, the translators are acting as mediators capable of overcoming certain ideological incompatibilities between the source writers and the French viewers, who might be flattered by the use of French icons as representative of class, but are more likely to dismiss the use of their language as part of a negative characterization process.

Finally, however asymmetrical the use of languages in contact in Frasier might seem, we should be particularly attentive to the changes operated in television comedy writing over the past decades. At the beginning we mentioned the transformation process that Fawlty Towers underwent in the Catalan version. Zabalbeascoa does not mention, though, that when the programme was dubbed for the Spanish state television, the process went even further: Manuel did not only change nationalities, he also changed languages and became Italian, signalling that the translators were aware of the threatening nature of the original script for a Spanish-speaking audience of any nationality. Fawlty Towers also made use of French characters and the French language, and once again French was associated with sophistication and glamour. However, in the British sitcom the asymmetric representation of languages in contact was clear-cut: Spanish was the language of the waiters whereas French was used by the guests. Frasier offers a good example of the evolution of language contact in television comedy at a time when Spanish is more likely to be used by the guests of London's hotels than by the waiters. French represents prestige but also snobbery. Spanish, on the other hand, has become part of the primary speech of English speakers. The Spanish-speaking characters in the sitcom might not be fluent in English ... yet, but they are very articulate in other languages such as German. In this sense, Frasier is another step reflecting the nature of change in the UK and the US, when compared with Fawlty Towers, for instance. This step has been taken even further by the script writers of Will \& Grace, a sitcom where various typologies (sexual, economic, cultural, linguistic) are challenged through the presentation of successful homosexual characters or authoritarian Spanish-speaking maids being perfectly fluent in English. 


\section{Bibliography}

Biber, Douglas, et al. (eds) (1999). Longman Grammar of Spoken and Written English. Harlow: Longman.

Brownlie, Siobhan (2003). "Distinguishing Some Approaches to Translation Research". The Translator 9(1), 39-64.

Fairclough, Norman (1992). "Discourse and Text: Linguistic and Intertextual Analysis within Discourse Analysis". Discourse \& Society 3(2), 193-217.

Fairclough, Norman (1995). Critical Discourse Analysis: The Critical Study of Language. London/New York: Longman.

Fairclough, Norman (2001 [1989]). Language and Power. Harlow: Longman.

Halliday Michael A. K. \& Ruqaiya Hasan (1976). Cohesion in English. Harlow: Longman.

Hartley, Nick, et al. The Frasier Files. On line at: http://www.geocities.com/Hollywood/Derby/3267/ (consulted AugustDecember 2004).

Hatim, Basil \& Ian Mason (1990). Discourse and the Translator. London/New York: Longman.

Hatim, Basil \& Ian Mason (1997). The Translator as Communicator. London: Routledge.

Heiss, Christine (2004). "Dubbing Multilingual Films: A New Challenge". Meta XLIX (1), 208-220.

Hermans, Theo (1999). Translation in Systems. Descriptive and Systemic Approaches Explained. Manchester: St Jerome.

Olk, Harald (2002). "Critical Discourse Awareness in Translation". The Translator 8(1), 101-116.

Phillipson, Robert (1992). Linguistic Imperialism. Oxford: Oxford UP.

Phillipson, Robert (2003). English Only Europe? Challenging Language Policy. London/New York: Routledge.

Thomason, Sarah G. (2001). Language Contact. Edinburgh: Edinburgh UP.

Venuti, Lawrence (1998). The Scandals of Translation. London/New York: Routledge.

Widdowson, Henry (1994). "The Ownership of English”. TESOL Quarterly 28, 377-388.

Zabalbeascoa, Patrick (1994). "Factors in Dubbing Television Comedy". Perspectives: Studies in Translatology 2(1), 89-99.

Zabalbeascoa, Patrick (1996). "Translating Jokes for Dubbed Television Situation Comedies". The Translator 2(2), 235-257. 